\title{
Morfoanatomia das brácteas em Heliconia (Heliconiaceae) ocorrentes no Estado de São Paulo, Brasil
}

\author{
Daniela Guimarães Simão ${ }^{1,2}$ e Vera Lucia Scatena ${ }^{1}$
}

Recebido em 10/01/2003. Aceito em 18/08/2003

\begin{abstract}
RESUMO - (Morfoanatomia das brácteas em Heliconia (Heliconiaceae) ocorrentes no Estado de São Paulo, Brasil). Foram estudados os caracteres morfoanatômicos das brácteas em $H$. rivularis, $H$. spathocircinata e $H$. velloziana (subg. Heliconia) e em $H$. angusta, H. hirsuta e H. subulata subsp. gracilis (subg. Stenochlamys), ocorrentes no Estado de São Paulo. As espécies do subg. Heliconia apresentam brácteas cimbiformes, enquanto as do subg. Stenochlamys apresentam brácteas lanceolado-conduplicadas. Todas as espécies apresentam brácteas com epiderme unisseriada, com células de paredes finas, estômatos tetracíticos em $H$. hirsuta e $H$. subulata e policíticos nas demais espécies; feixes vasculares e canais de ar distribuídos em forma de arco; e feixes de fibras situados próximos à superfície abaxial. A forma das brácteas, associada à distribuição e localização dos feixes de fibras na região abaxial e ao tamanho dos canais de ar no mesofilo difere nos dois subgêneros estudados, constituindo caracter de valor taxonômico. Foi elaborada uma chave de identificação usando os caracteres morfoanatômicos.
\end{abstract}

Palavras-chave: anatomia, morfologia, brácteas, Heliconia, Heliconiaceae

\begin{abstract}
Morphology and anatomy of the bracts in Heliconia (Heliconiaceae), occurring in the São Paulo State, Brazil). The morphological and anatomical features of the inflorescence bracts were studied in H. rivularis, H. spathocircinata and $H$. velloziana (subg. Heliconia) and in H. angusta, H. hirsuta and H. subulata subsp. gracilis (subg. Stenochlamys). All species are found in São Paulo State. In the subg. Heliconia the bracts are cymbiform and in Stenochlamys they are lanceolate-conduplicated. All species have bracts with uniseriate epidermis, with thin-walled cells, tetracytical stomata in $H$. hirsuta and $H$. subulata, and polycytical in the others; the vascular bundles and air canals are distributed in arc-shaped and the fiber bundles are situated close to the abaxial surface. The bract shape, associated with the distribution of the fiber bundles and with the size of the air canals were different in both studied subgenera. An identification key was made based on morphological and anatomical features.
\end{abstract}

Key words: anatomy, morphology, bracts, Heliconia, Heliconiaceae

\section{Introdução}

A família Heliconiaceae apresenta 200 a 250 espécies de ocorrência neotropical, embora ocorra um pequeno grupo paleotropical, cerca de seis espécies, nas ilhas do Pacífico Sul (Kress 1990a; Andersson 1998). Existem cerca de 40 espécies nativas no Brasil, com alto grau de endemismo na floresta atlântica costeira, que juntamente com a bacia do rio Amazonas, correspondem às áreas primárias de distribuição do gênero no país (Kress 1990b).

As inflorescências de Heliconia são tirsiformes, cada inflorescência parcial correspondendo a um cincino (Dahlgren et al. 1985; Andersson 1998). Nas espécies neotropicais os cincinos são envoltos por brácteas de coloração viva, enquanto nas espécies paleotropicais as brácteas são verdes, sendo que a coloração está relacionada às síndromes de polinização, ornitofilia e quiropterofilia, respectivamente (Dahlgren et al. 1985; Berry \& Kress 1991; Andersson 1998). As brácteas também protegem botões florais e frutos em desenvolvimento (Endress 1994).

Em Heliconia as brácteas podem ser cimbiformes ou lanceolado-conduplicadas, sendo um dos caracteres importantes na separação dos quatro subgêneros existentes em Heliconiaceae: Taeniostrobus Kuntze (Griggs); Griggsia Andersson; Stenochlamys Baker e Heliconia (Andersson 1981; 1985; 1992). Os subgêneros Stenochlamys e Heliconia apresentam o maior número de espécies distribuídas no Brasil (Kress 1990b; Andersson 1992).

Estudos anatômicos das brácteas realizados com espécies de monocotiledôneas, como em Eriocaulaceae e Bromeliaceae (Tomlinson 1969) mostram que as brácteas constituem importante caracter taxonômico. Em Heliconia, Andersson (1985; 1992), utilizando a

1 Departamento de Botânica, Instituto de Biociências, UNESP, C. Postal 199, Av. 24-A, 1515, Bela Vista, CEP 13506-900, Rio Claro, SP, Brasil

2 Autor para correspondência: dgsimao@hotmail.com 
anatomia como ferramenta para a diferenciação dos subgêneros, mostrou que espécies com brácteas cimbiformes geralmente apresentam canais de ar grandes e numerosos feixes de fibras próximos à superfície abaxial. Já as espécies com brácteas lanceoladas apresentam canais de ar pequenos e número reduzido de feixes de fibras próximos à superfície abaxial.

O presente trabalho tem como objetivo caracterizar a morfoanatomia das brácteas em seis espécies de Heliconia pertencentes a dois subgêneros, encontrados no Estado de São Paulo: H. rivularis L. Emygd. \& E. Santos, $H$. spathocircinata Aristeg. e $H$. velloziana L. Emygd. (subg. Heliconia) e H. angusta Vell., $H$. hirsuta L. f. e H. subulata subsp. gracilis (Peters.) Anderss. (subg. Stenochlamys). As diferenças anatômicas entre as espécies poderão ser utilizadas na identificação desses representantes, complementando as informações já conhecidas para Heliconia.

\section{Material e métodos}

As espécies de Heliconia foram coletadas em quatro áreas do Estado de São Paulo. No Núcleo Picinguaba, Parque Estadual da Serra do Mar, município de Ubatuba, foram coletadas Heliconia angusta, $H$. rivularis, $H$. spathocircinata e H. velloziana. Na Base Saibadela, Parque Estadual Intervales, município de Sete Barras, foram coletadas $H$. spathocircinata e $H$. velloziana. Na Fazenda Palmital, propriedade particular, município de Amparo, foi coletada $H$. subulata subsp. gracilis. No Jardim Botânico Municipal de Bauru coletou-se H. hirsuta. Todas as espécies ocorrem em ambientes úmidos, no subosque de floresta atlântica costeira ou floresta estacional semidecidual, exceto $H$. hirsuta encontrada a pleno sol, nas proximidades de um cerradão.

As exsicatas estão depositadas no Herbarium Rioclarense (HRCB), Universidade Estadual Paulista, Rio Claro, sob as seguintes especificações: $H$. angusta: BRASIL. São Paulo: Ubatuba, 13/X/1996, Simão et al. 14; Ubatuba, 13/X/1996, Simão et al. 15. H. hirsuta: BRASIL. São Paulo: Bauru, 13/V/2001, Simão \& Mantovani 69. H. subulata subsp. gracilis: BRASIL. São Paulo: Amparo, 27/IX/2001, Simão \& Cardoso 91. H. rivularis: BRASIL. São Paulo: Ubatuba, 20/III/1998, Simão \& Mantovani 25; Ubatuba, 5/II/2002, Simão et al. 111. H. spathocircinata: BRASIL. São Paulo: Sete Barras, 13/I/2001, Zipparro 1850; Ubatuba, 4/II/2002, Simão et al. 107. H. velloziana: BRASIL. São Paulo:
Ubatuba, 25/III/1996, Simão et al. 4; Ubatuba, 14/X/1996, Simão et al. 16.

As brácteas foram fixadas em FAA 50 e posteriormente mantidas em etanol $70 \%$ (Johansen 1940). Para o estudo anatômico, foi selecionada a região mediana das brácteas basais, em pelo menos cinco indivíduos de cada espécie. Nestas amostras, foram realizadas secções à mão livre, transversais e paradérmicas, coradas com fucsina básica e azul de astra (Roeser 1972) e montadas em gelatina glicerinada. Amostras das brácteas também foram desidratadas em série etílica, incluídas em resina (glicolmetacrilato JB4/ Polysciences), seccionadas em micrótomo rotatório, coradas com azul de toluidina e fucsina básica (Kraus \& Arduin 1997) e montadas em Entellan. Foram realizados testes histoquímicos para detecção de substâncias pécticas (Sass 1951), fenóis e lignina (Johansen 1940) e amido (Bücherl 1962).

\section{Resultados}

Heliconia rivularis (Fig. 1), H. spathocircinata (Fig. 2, 3) e H. velloziana (Fig. 4) apresentam inflorescências com brácteas cimbiformes, enquanto que em H. angusta (Fig. 5), H. hirsuta (Fig. 6) e H. subulata subsp. gracilis (Fig. 7) as brácteas são lanceolado-conduplicadas. Em relação à orientação das brácteas, em $H$. rivularis (Fig. 1) e $H$. spathocircinata (Fig. 2, 3) as brácteas estão dispostas em espiral; as demais espécies apresentam brácteas dísticas (Fig. 4-7). As margens das brácteas são planas, exceto em H. spathocircinata (Fig. 2, 3) com margens involutas. Esta última espécie e H. rivularis (Fig. 1) apresentam brácteas com ápice circinado. Em todas as espécies a coloração externa e interna das brácteas varia desde amarela até rósea, sendo que $H$. spathocircinata apresenta variação na coloração (Tab. 1). As flores podem estar parcial ou totalmente expostas nas brácteas (Tab. 1).

Nos diagramas das secções transversais das brácteas observa-se o mesmo padrão anatômico para todas as espécies: distribuição periférica abaxial de feixes de fibras, e canais de ar e feixes vasculares distribuídos em arcos no mesofilo (Fig. 8-15).

Os feixes de fibras estão localizados próximos à face abaxial, sendo que em algumas espécies eles se alternam com feixes vasculares (Fig. 11,12, 14, 15). Em H. rivularis (Fig. 8, 9), H. velloziana (Fig. 10) e H. spathocircinata (Fig. 11, 12) estes feixes de fibras estão distribuídos muito próximos uns dos outros, em grande quantidade, e com localização bem próxima à 


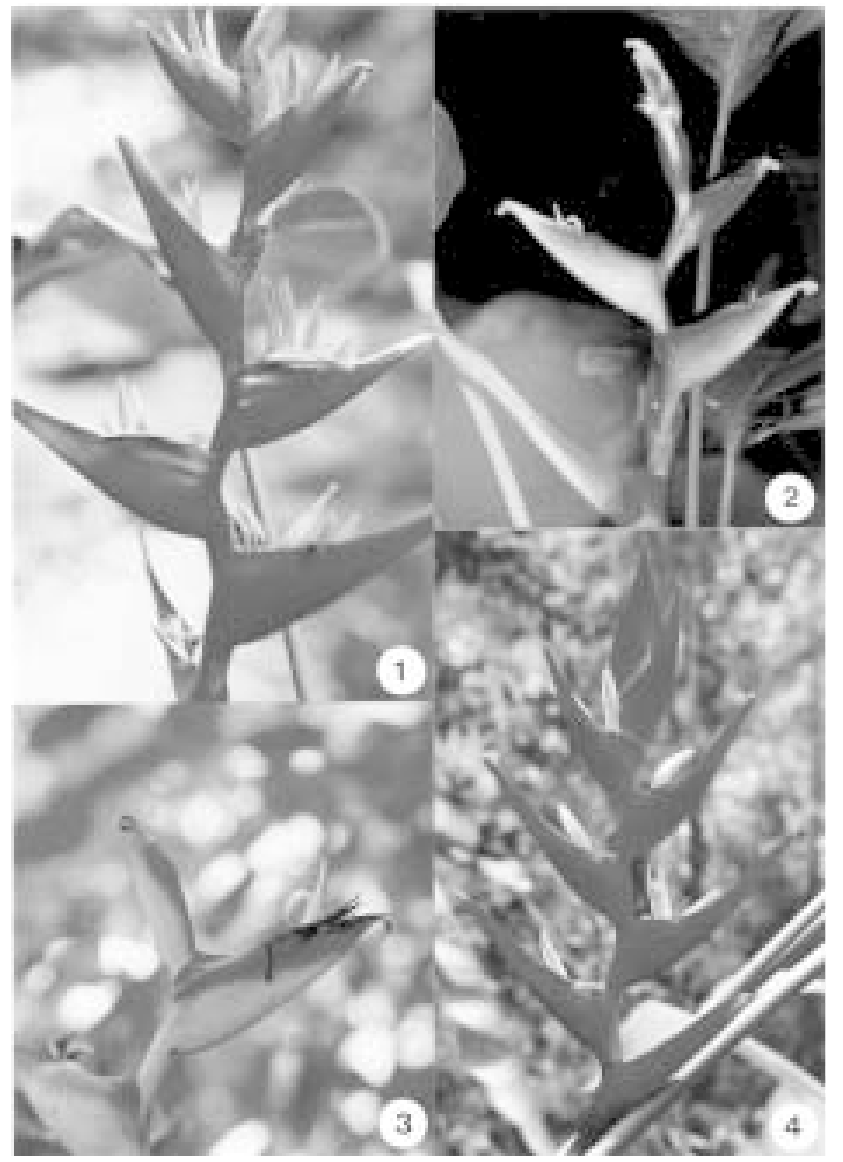

Figuras 1-4. Inflorescências de Heliconia, subg. Heliconia. 1. Heliconia rivularis, com brácteas cimbiformes, dispostas em espiral, com perianto totalmente exposto. 2. Heliconia spathocircinata, com brácteas cimbiformes, dispostas em espiral, com perianto parcialmente exposto. 3. Heliconia spathocircinata, com brácteas cimbiformes, dispostas em espiral, com perianto parcialmente exposto. 4. Heliconia velloziana, com brácteas cimbiformes, dísticas, com perianto parcialmente exposto.

epiderme abaxial. Em H. hirsuta (Fig. 14) a distribuição dos feixes de fibras é espaçada, enquanto em H. angusta (Fig. 13) e H. subulata (Fig. 15) ocorrem poucos feixes de fibras. A localização das fibras nestas três últimas espécies é mais distante da epiderme abaxial (Fig. 13-15), quando comparada com as anteriores (Fig. 8-12).

Os canais de ar estão distribuídos na forma de arco, em toda a extensão da bráctea, exceto nas extremidades, como pode ser observado em H. rivularis (Fig. 8).

Os feixes vasculares estão dispostos em um arco principal, que se alterna com os canais de ar, e em outro arco abaxial, formado por uma a duas séries de feixes vasculares menores (Fig. 8-15).
Em vista frontal da epiderme observa-se que os estômatos são tetracíticos em $H$. hirsuta (Fig. 17) e H. subulata (Fig. 18), enquanto nas demais espécies são policíticos, com até quatro células laterais e quatro células polares (Fig. 16, 19, 20). Ocorrem nas duas faces da epiderme, com maior freqüência na face abaxial. Em $H$. subulata não ocorrem estômatos na face adaxial.

As demais células epidérmicas possuem formato variado, ocorrendo desde isodiamétricas até retangulares, com predomínio deste último formato na maioria das espécies (Fig. 16-20). As células epidérmicas formam fileiras no sentido longitudinal do comprimento da bráctea, em ambas as faces, e apresentam paredes estreitas. Na face abaxial intercalam-se com estômatos de forma bem regular, como em H. hirsuta (Fig. 17) ou menos regular, como em $H$. rivularis (Fig. 16).

Em $H$. rivularis (Fig. 16), H. spathocircinata e $H$. velloziana foram observados tricomas pluricelulares, em sua maioria, na superfície abaxial.

Em secções transversais do mesofilo, observa-se que as células parenquimáticas do mesofilo, situadas próximas à face abaxial, são arredondadas, sendo mais alongadas na região adaxial como observa-se em H. subulata (Fig. 24).

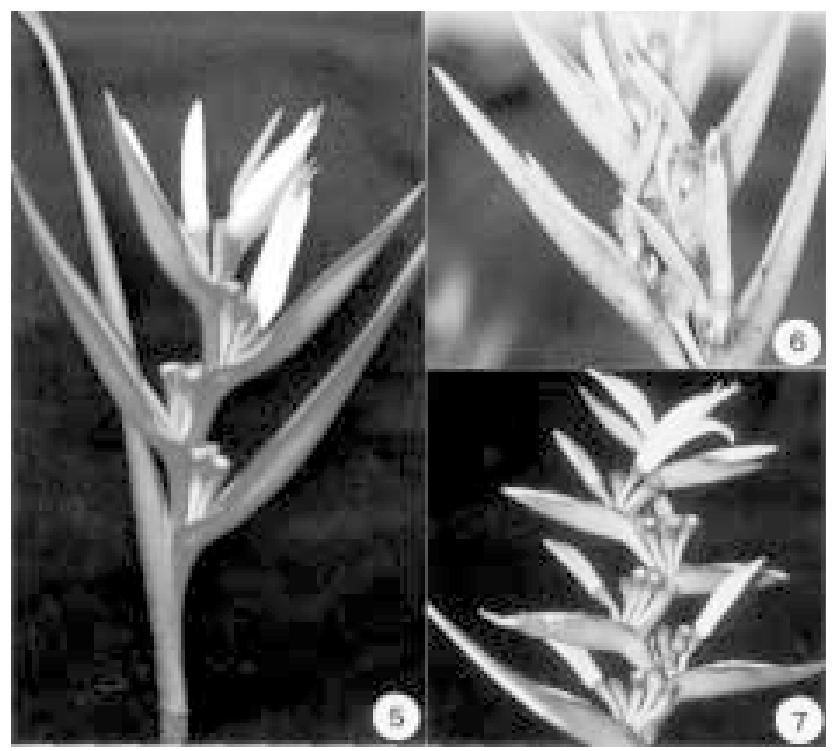

Figuras 5-7. Inflorescências de Heliconia, subg. Stenochlamys. 5. Heliconia angusta, com brácteas lanceolado-conduplicadas, dísticas, com flores totalmente expostas. 6. Heliconia hirsuta, com brácteas lanceolado-conduplicadas, dísticas, com flores totalmente expostas. 7. Heliconia subulata subsp. gracilis com brácteas lanceolado-conduplicadas, dísticas, com flores totalmente expostas. 
Tabela 1. Caracteres morfoanatômicos das brácteas em Heliconia ocorrentes no Estado de São Paulo.

\begin{tabular}{|c|c|c|c|c|c|c|}
\hline \multirow{3}{*}{ Caracteres } & \multicolumn{6}{|c|}{ Espécies } \\
\hline & \multicolumn{3}{|c|}{ Subgênero Heliconia } & \multicolumn{3}{|c|}{ Subgênero Stenochlamys } \\
\hline & H. rivularis $I$ & H. spathocircinata & H. velloziana & H. hirsuta & $\begin{array}{l}\text { H. subulata } \\
\text { subsp. gracilis }\end{array}$ & H. angusta \\
\hline Formato das brácteas & cimbiformes & cimbiformes & $\begin{array}{l}\text { cimbiformes } \\
\text { conduplicadas }\end{array}$ & $\begin{array}{l}\text { lanceolado- } \\
\text { conduplicadas }\end{array}$ & $\begin{array}{l}\text { lanceolado- } \\
\text { conduplicadas }\end{array}$ & $\begin{array}{l}\text { lanceolado- } \\
\text { conduplicadas }\end{array}$ \\
\hline Orientação das brácteas & espiraladas & espiraladas & dísticas & dísticas & dísticas & dísticas \\
\hline Margens das brácteas & planas & involutas & planas & planas & planas & planas \\
\hline Ápice das brácteas & $\begin{array}{l}\text { ligeiramente } \\
\text { circinado }\end{array}$ & circinado & plano & plano & plano & plano \\
\hline $\begin{array}{l}\text { Coloração externa das } \\
\text { brácteas }\end{array}$ & $\begin{array}{c}\text { laranja- } \\
\text { avermelhadas }\end{array}$ & $\begin{array}{c}\text { laranja- } \\
\text { avermelhadas } \\
\text { amarelas com } \\
\text { margens vermelhas }\end{array}$ & $\begin{array}{l}\text { vermelho- } \\
\text { alaranjadas }\end{array}$ & alaranjadas & róseas & $\begin{array}{l}\text { vermelho- } \\
\text { rosadas }\end{array}$ \\
\hline $\begin{array}{l}\text { Coloração interna } \\
\text { das brácteas }\end{array}$ & alaranjada & amarelada & $\begin{array}{l}\text { vermelho- } \\
\text { alaranjadas }\end{array}$ & alaranjadas & róseas & $\begin{array}{l}\text { vermelho- } \\
\text { rosadas }\end{array}$ \\
\hline $\begin{array}{l}\text { Exposição das flores } \\
\text { nas brácteas }\end{array}$ & $\begin{array}{l}\text { perianto } \\
\text { totalmente } \\
\text { exposto }\end{array}$ & $\begin{array}{l}\text { perianto } \\
\text { parcialmente } \\
\text { exposto }\end{array}$ & $\begin{array}{l}\text { perianto } \\
\text { parcialmente } \\
\text { exposto }\end{array}$ & $\begin{array}{l}\text { flores } \\
\text { totalmente } \\
\text { expostas }\end{array}$ & $\begin{array}{l}\text { flores } \\
\text { totalmente } \\
\text { expostas }\end{array}$ & $\begin{array}{l}\text { flores } \\
\text { totalmente } \\
\text { expostas }\end{array}$ \\
\hline $\begin{array}{l}\text { Distribuição dos feixes } \\
\text { de fibras no mesofilo }\end{array}$ & $\begin{array}{l}\text { feixes de fibras } \\
\text { próximos uns } \\
\text { dos outro }\end{array}$ & $\begin{array}{l}\text { feixes de fibras } \\
\text { próximos uns } \\
\text { dos outro }\end{array}$ & $\begin{array}{l}\text { feixes de fibras } \\
\text { próximos uns } \\
\text { dos outro }\end{array}$ & $\begin{array}{c}\text { vários feixes } \\
\text { de fibras } \\
\text { espaçados }\end{array}$ & $\begin{array}{l}\text { poucos feixes } \\
\text { de fibras } \\
\text { espaçados }\end{array}$ & $\begin{array}{c}\text { poucos feixes } \\
\text { de fibras } \\
\text { espaçados }\end{array}$ \\
\hline $\begin{array}{l}\text { Localização dos feixes } \\
\text { de fibras no mesofilo }\end{array}$ & $\begin{array}{l}\text { bem próximo } \\
\text { à epiderme } \\
\text { abaxial }\end{array}$ & $\begin{array}{l}\text { bem próximo } \\
\text { à epiderme } \\
\text { abaxial }\end{array}$ & $\begin{array}{l}\text { bem próximo } \\
\text { à epiderme } \\
\text { abaxial }\end{array}$ & $\begin{array}{l}\text { distante da } \\
\text { epiderme } \\
\text { abaxial }\end{array}$ & $\begin{array}{l}\text { distante da } \\
\text { epiderme } \\
\text { abaxial }\end{array}$ & $\begin{array}{l}\text { distante da } \\
\text { epiderme } \\
\text { abaxial }\end{array}$ \\
\hline $\begin{array}{l}\text { Distribuição dos canais } \\
\text { de ar no mesofilo }\end{array}$ & grande parte & grande parte & grande parte & pequena parte & pequena parte & pequena parte \\
\hline Estômatos & policíticos & policíticos & policíticos & tetracíticos & tetracíticos & policíticos \\
\hline Tricomas pluricelulares & presentes & presentes & presentes & ausentes & ausentes & ausentes \\
\hline
\end{tabular}

O mesofilo de $H$. rivularis (Fig. 8, 9), H. velloziana (Fig. 10) e H. spathocircinata (Fig. 11, 12) é ocupado em grande parte pelos canais de ar, diferentemente das outras três espécies (Fig. 13-15) que apresentam canais de ar menores. Estes canais de ar formam compartimentos delimitados por diafragmas, que por sua vez são constituídos por células braciformes, como pode ser observado em H. spathocircinata (Fig. 21). Quando a secção passa no canal, entre as células braciformes, observa-se apenas a lacuna (Fig. 22-24).

Geralmente são encontrados idioblastos contendo ráfides nas células braciformes (Fig. 21) e em todo o mesofilo, principalmente na porção abaxial próxima aos feixes de fibras, como pode ser observado em H. hirsuta e H. subulata (Fig. 25, setas).

Os feixes vasculares são colaterais e diferem entre si pela quantidade de tecidos que os constituem e quantidade de fibras a eles associados. São envolvidos externamente pela endoderme e internamente apresentam calotas de fibras pericíclicas externas ao xilema e ao floema (Fig. 21-25). Os feixes vasculares próximos aos canais de ar são mais alongados do que os demais, e parcialmente envoltos por fibras, que formam arcos sobre o floema e, em menor quantidade sobre o xilema (Fig. 21, 23, 24). Já os feixes vasculares próximos à superfície abaxial são menores e apresentam maior quantidade de fibras, principalmente junto ao floema (Fig. 21, 23, 24). Alguns feixes próximos à epiderme abaxial são completamente envoltos por fibras.

Os caracteres morfológicos e anatômicos das brácteas estão agrupados na Tabela 1. A partir destes caracteres, elaborou-se uma chave de identificação, apresentada a seguir. 


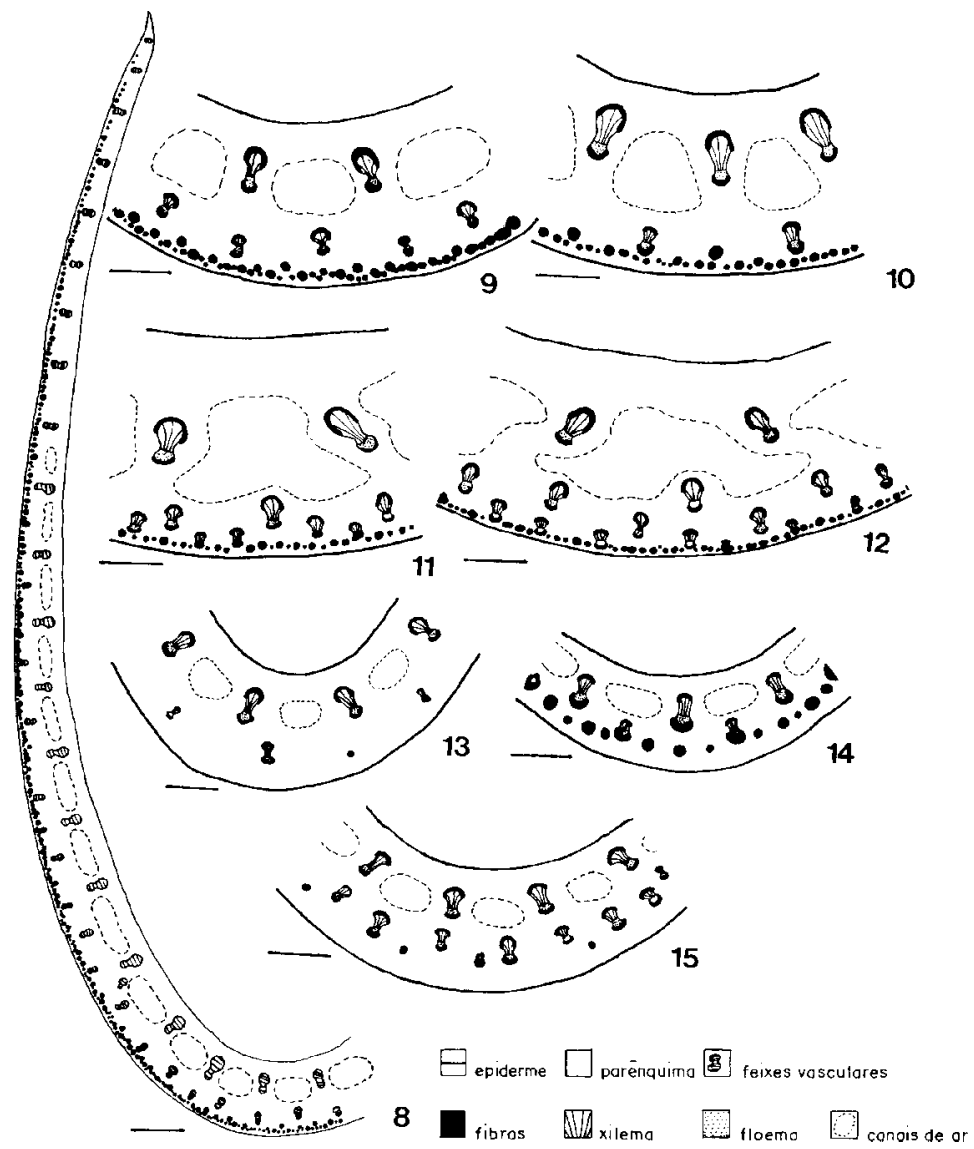

Figuras 8-15. Diagramas das secções transversais da região mediana, das brácteas basais em espécies de Heliconia. 8, 9. Heliconia rivularis. Barra em $8=1,0 \mathrm{~mm}$. 10. Heliconia velloziana. 11. Heliconia spathocircinata variedade de brácteas alaranjadas. 12 . Heliconia spathocircinata variedade de brácteas amarelas. 13. Heliconia angusta 14. Heliconia hirsuta. Barras em 9-14 = 0,5mm. 15. Heliconia subulata subsp. gracilis. Barra $=1,0 \mathrm{~mm}$.

Chave de identificação das espécies de Heliconia ocorrentes no Estado de São Paulo, baseada nos caracteres morfoanatômicos das brácteas

1. Brácteas cimbiformes; flores parcialmente expostas nas inflorescências; feixes de fibras próximos uns dos outros na região abaxial, junto à epiderme abaxial; canais de ar ocupando grande parte do mesofilo; tricomas pluricelulares presentes nas brácteas

2. Brácteas dísticas

H. velloziana

2. Brácteas em espiral

3. Margens planas; perianto totalmente à mostra

H. rivularis

3. Margens involutas na região proximal; perianto parcialmente à mostra

4. Brácteas laranja-avermelhadas

H. spathocircinata

4. Brácteas amarelas com margens vermelhas

H. spathocircinata

1. Brácteas lanceolado-conduplicadas; flores totalmente expostas nas inflorescências; feixes de fibras espaçados uns dos outros na região abaxial, nas proximidades da epiderme abaxial; canais de ar ocupando pequena parte do mesofilo; tricomas pluricelulares ausentes nas brácteas

5. Mais de três feixes de fibras na região mediano-abaxial das brácteas

H. hirsuta

5. Até três feixes de fibras na região mediano-abaxial das brácteas

6. Um feixe de fibras na região mediano-abaxial; estômatos em ambas as faces

H. angusta

6. Três feixes de fibras na região mediano-abaxial; estômatos somente na face abaxial 


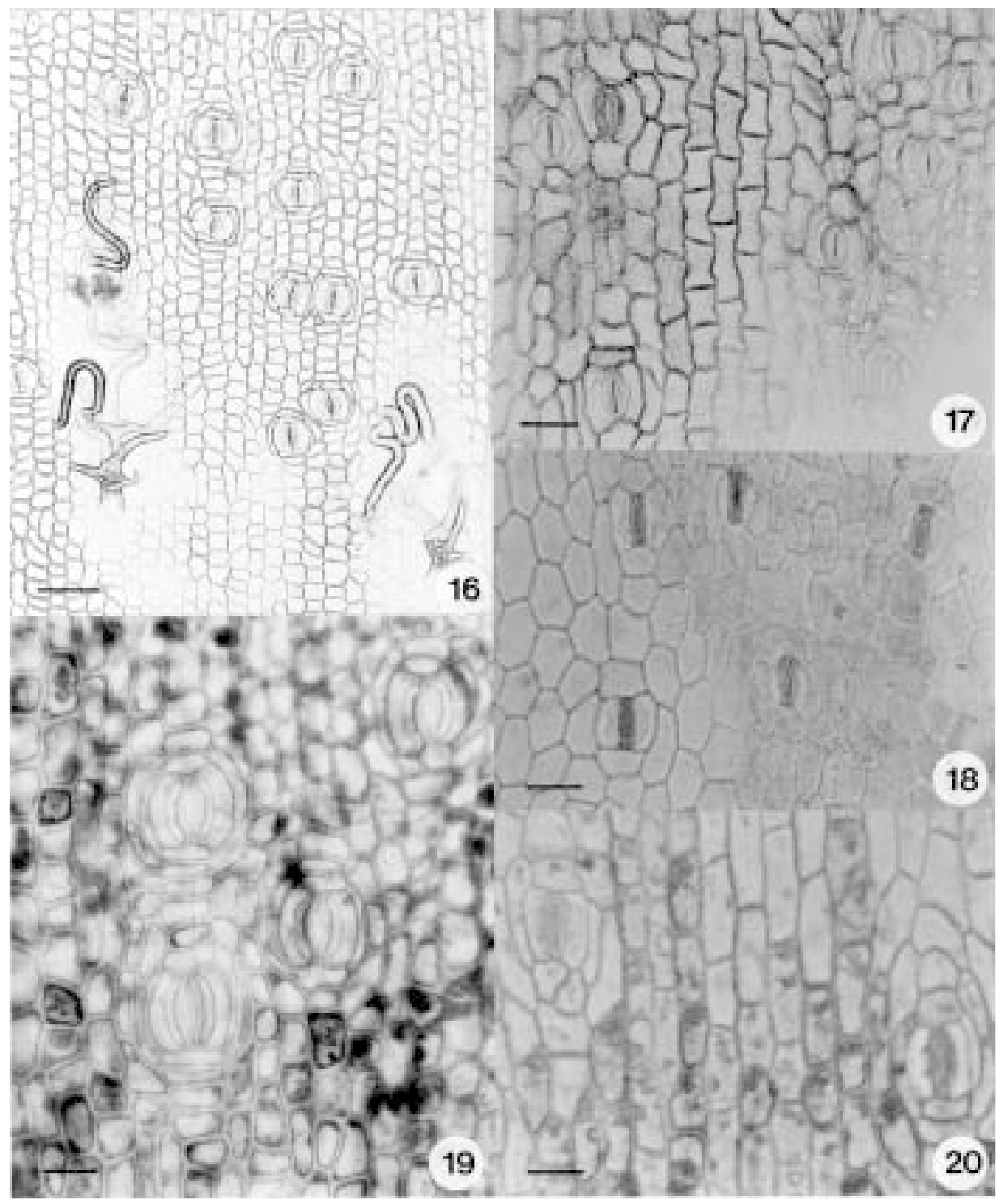

Figuras 16-20. Vista frontal da epiderme das brácteas de Heliconia. 16. Células epidérmicas abaxiais de Heliconia rivularis, com estômatos policíticos e tricomas. Barra $=70 \mu \mathrm{m}$. 17. Células epidérmicas abaxiais de Heliconia hirsuta, com estômatos tetracíticos. 18. Células epidérmicas abaxiais de Heliconia subulata subsp. gracilis, com estômatos tetracíticos. 19. Células epidérmicas abaxiais de Heliconia velloziana, com estômatos policíticos. 20. Células epidérmicas abaxiais de Heliconia angusta, com estômatos policíticos. Barras em 17-20 $=30 \mu \mathrm{m}$.

\section{Discussão}

De todas as espécies estudadas apenas H. spathocircinata apresenta polimorfismo, com variação na coloração das brácteas, confirmando o que foi relatado por Andersson (1985) para esta espécie. De acordo com o autor, o polimorfismo em Heliconia é bastante comum, dificultando o tratamento taxonômico para o gênero. Este mesmo autor sugeriu que fatores ambientais, como por exemplo, grandes mudanças climáticas nas áreas de ocorrência destas espécies, contribuíram para o polimorfismo em
Heliconiaceae, através de dois mecanismos: diferenciação devido ao isolamento e convergência devido ao contato secundário e à hibridização.

A estrutura anatômica das brácteas de Heliconia é semelhante à das folhas (Triplett \& Kirchoff 1991), principalmente na região das bainhas (Tomlinson 1959; 1962; Simão \& Scatena 2001). Epiderme unisseriada formada por células de paredes finas, feixes vasculares e canais de ar distribuídos em forma de arco, presença de feixes de fibras próxima à superfície abaxial, caracterizam tanto as brácteas das espécies estudadas, quanto as das Heliconia estudadas por estes autores. 


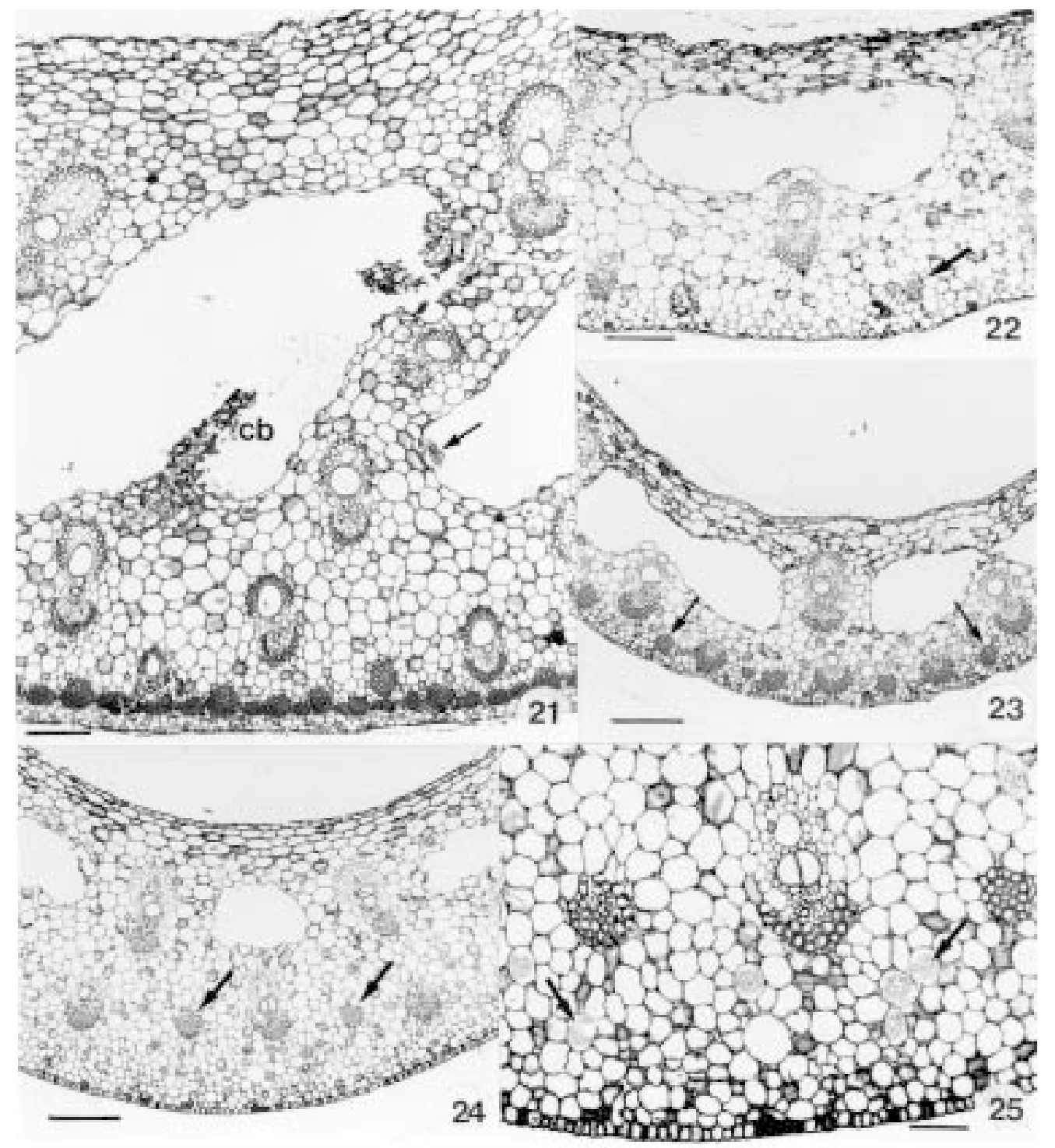

Figuras 21-25. Região mediana das brácteas de Heliconia, em secção transversal. 21. Heliconia spathocircinata com canal de ar, feixes vasculares e feixes de fibras próximos uns dos outros na região abaxial. cb: células braciformes, seta: ráfide. 22. Heliconia angusta com apenas um feixe de fibras (seta). 23. Heliconia hirsuta com feixes de fibras (setas) espaçados uns dos outros. 24. Heliconia subulata

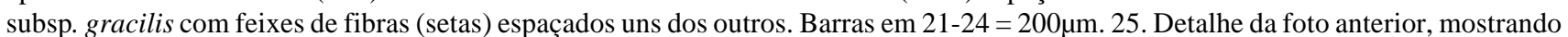
um feixe vascular entre feixes de fibras e os idioblastos contendo ráfides (setas). Barra $=70 \mu \mathrm{m}$.

Dentre esses caracteres, a distribuição e a localização dos feixes de fibras parece ser o melhor para separar as espécies dentro dos subgêneros de Heliconia. Observou-se que a ocorrência deste carater está diretamente relacionada à forma das brácteas.

Assim, $H$. rivularis, $H$. spathocircinata e $H$. velloziana apresentam brácteas cimbiformes e vários feixes de fibras próximos uns dos outros, junto à epiderme abaxial, caracterizando um agrupamento uniforme, confirmado pelas revisões taxonômicas que as incluem no subgênero Heliconia (Andersson 1992).
Nas espécies com brácteas lanceolado-conduplicadas, $H$. hirsuta possui feixes de fibras espaçados, enquanto em $H$. angusta e $H$. subulata esta distribuição é bem mais espaçada, os feixes ocupam posição mais afastada da epiderme abaxial. Para estas espécies, pertencentes ao subgênero Stenochlamys, este carater não se mostrou uniforme e portanto elas não podem ser agrupadas de maneira natural como aquelas do subgênero Heliconia. Segundo Andersson (1985; 1992) o subgênero Stenochlamys apresenta considerável variação na anatomia das brácteas corroborando com o que foi apresentado acima. 
Outro carater anatômico que varia nas espécies estudadas é o tipo de estômato. Nas espécies do subgênero Heliconia e em $H$. angusta, pertencente ao subgênero Stenochlamys, os estômatos possuem até oito células subsidiárias, aqui denominados policíticos, enquanto que nas demais espécies, pertencentes ao subgênero Stenochlamys, ocorrem quatro células subsidiárias, i.e., estômatos tetracíticos. Estes resultados também foram relatados por Dahlgren et al. (1985) e Andersson (1998) para as folhas de Heliconia. Para Tomlinson $(1969 ;$ 1974), o desenvolvimento do complexo estomático é bem elaborado nas lâminas foliares de Heliconia, pois os estômatos são formados por duas células subsidiárias laterais e duas terminais, entretanto outras células menores podem estar presentes, como aqui observado.

O número de células subsidiárias, apesar de variado em Heliconia, não é um carater taxonômico importante dentro da ordem Zingiberales, da qual Heliconiaceae pertence, e sim a simetria das células-guarda segundo Tomlinson (1962), Kress (1990a) e Kress et al. (2001). Para Stebbins \& Khush (1961), os representantes da ordem Zingiberales, apresentam células subsidiárias que não são bem diferenciadas das demais células epidérmicas foliares. Como pode ser constatado para outras Heliconiaceae, ocorre variação no número de células subsidiárias dos estômatos, o que foi confirmado também neste trabalho para as Heliconia estudadas, mesmo que para o subgênero Heliconia este seja um carater que agrupa as espécies.

Das espécies estudadas apenas $H$. hirsuta ocorre a pleno sol; as demais espécies crescem em ambientes sombreados. $H$. hirsuta apresentou um maior número de estômatos, principalmente na face abaxial, quando comparada com as demais espécies estudadas, confirmando as informações de Rundel et al. (1998). Ainda de acordo com Rundel et al. (1998) as diferenças encontradas na estrutura foliar das espécies de Heliconia podem ser ocasionadas pelas diferentes condições luminosas.

As brácteas de todas as espécies estudadas apresentam idioblastos contendo ráfides, nas células braciformes dos canais de ar e em toda a extensão do mesofilo, principalmente próximo aos feixes de fibras. A presença de ráfides nos órgãos vegetativos de Heliconia foi relatada por Tomlinson $(1959 ; 1962)$, Finley (1999) e Simão \& Scatena (2001). Segundo os autores, os idioblastos com ráfides são encontrados nos parênquimas paliçádico e esponjoso das lâminas foliares, nas células braciformes dos canais de ar das bainhas e dos pecíolos, e na região cortical de rizomas e raízes. Tais idioblastos podem estar relacionados aos mecanismos de defesa da planta contra herbívoros. Estes idioblastos também são observados nos botões florais, nas flores e nos frutos de espécies de Heliconia (Simão et al. em preparação).

De acordo com Metcalfe (1969) e Franceschi \& Horner (1980) a ocorrência de cristais nas plantas é muito específica dentro de determinados táxons, sugerindo que sua presença seja determinada geneticamente. Por exemplo, em Zingiberales a presença ou não das ráfides divide a ordem em dois grupos (Tomlinson 1962; Kress et al. 1990a; Kress et al. 2001). Para estes autores a presença destes cristais, encontrado nas Heliconiaceae, Musaceae, Strelitiziaceae e Lowiaceae, constitui um caracter plesiomórfico na ordem.

O interior de algumas brácteas, principalmente de $H$. spathocircinata e de $H$. velloziana, que ocorrem tanto na Base Saibadela como no Núcleo Picinguaba, acumula líquido, aparentemente água de chuva, já que nestas duas áreas a pluviosidade média anual é alta. Bronstein (1986) e Wootton \& Sun (1990) afirmaram que o líquido encontrado no interior das brácteas, principalmente nas brácteas cimbiformes das espécies de Heliconia, seja uma secreção da própria bráctea. Geralmente as brácteas de Heliconia atraem grande quantidade de artrópodes aquáticos, principalmente larvas de moscas, besouros e de alguns homópteros (Thompson 1997). Este líquido protegeria, então, flores e frutos submersos da ação dos herbívoros (Bronstein 1986; Wootton \& Sun 1990). De acordo com Wootton \& Sun (1990) esta redução na herbivoria das flores e frutos influencia no sucesso reprodutivo destas espécies. Ainda segundo Wootton \& Sun (1990) aquelas espécies que não secretam líquido, como as helicônias de inflorescência pendente, desenvolveram outros mecanismos de defesa contra a herbivoria, como brácteas e flores mais compactas, além de tricomas.

Bronstein (1986) sugeriu que o líquido seria transportado diretamente do caule para cada uma das brácteas na inflorescência, e que um estudo mais preciso da estrutura das brácteas poderá revelar a presença de células secretoras. No presente trabalho constatamos que não existe nenhuma estrutura secretora especializada nas brácteas e nem no eixo da inflorescência (obs. pessoal) das seis espécies estudadas. Devido a forma das brácteas, acredita-se que, possivelmente, este líquido seja proveniente da água da chuva e do néctar floral, aí acumulados. 
De acordo com a chave de identificação, elaborada a partir dos caracteres morfoanatômicos, e como discutido anteriormente, os principais caracteres que permitem separar os subgêneros são: forma das brácteas, associada à distribuição e localização dos feixes de fibras na região abaxial e ao tamanho dos canais de ar no mesofilo.

Entre as espécies do subgênero Stenochlamys (H. hirsuta, $H$. subulata e $H$. angusta), observa-se que as características anatômicas são mais variáveis do que as morfológicas, já que os feixes de fibras são sempre espaçados uns dos outros, embora variem em número. Já entre as espécies do subgênero Heliconia ( $H$. rivularis, $H$. spathocircinata e $H$. velloziana) as características morfológicas das brácteas, como disposição na inflorescência e modo de exposição do perianto, foram mais distintas do que as anatômicas, possibilitando a separação das espécies. Já características epidérmicas, como presença ou não de tricomas e tipos de estômatos variam entre as espécies, e não podem ser utilizadas para separar os subgêneros, tendo portanto importância apenas em nível específico.

\section{Agradecimentos}

À FAPESP, pelo apoio financeiro (Processo n. 00/02345-5); ao Instituto Florestal (Núcleo Picinguaba), à Fundação Florestal (Base Saibadela); ao Jardim Botânico Municipal de Bauru e ao Sr. Djalma Zabeu, pela permissão de pesquisa; a João Marcelo Alvarenga Braga pela identificação das espécies; e a Cristiano Marcelo Viana Cardoso, Adelar Mantovani, Cristina Guimarães Simão e Valesca Bononi Zipparro, pelo auxílio nos trabalhos de campo.

\section{Referências bibliográficas}

Andersson, L. 1981. Revision of Heliconia sect. Heliconia (Musaceae). Nordic Journal of Botany 1(6): 759-784.

Andersson, L. 1985. Revision of Heliconia subgen. Stenochlamys (Musaceae - Heliconioideae). Opera Botanica 82: 1-124.

Andersson, L. 1992. Revision of Heliconia subgen. Taeniostrobus and subgen. Heliconia (Musaceae Heliconioideae). Opera Botanica 111: 1-98.

Andersson, L. 1998. Heliconiaceae. Pp. 226-230. In: K. Kubitzki (ed.). The Families and Genera of Vascular Plants. IV. Flowering Plants. Monocotyledons. Alismatanae and Commelinanae (except Gramineae). Springer, Berlin.
Berry, F. \& Kress, J. 1991. Heliconia - An identification guide. Smithsonian Institution Press. Washington. 334p.

Bronstein, J.L. 1986. The origin of bract liquid in a Neotropical Heliconia species. Biotropica 18(2): 111-114.

Bücherl, W. 1962. Técnica microscópica. $3^{\mathrm{a}}$ ed. Editora Polígono Ltda, São Paulo.

Dahlgren, R.M.T.; Clifford, H.T. \& Yeo, P.F. 1985. The families of the monocotyledons. Springer-Verlag, Berlin.

Endress, P.K. 1994. Diversity and evolutionary biology of tropical flowers. Cambridge University Press.

Finley, D.S. 1999. Patterns of calcium oxalate crystals in young tropical leaves: a possible role as an antiherbivory defense. Revista de Biologia Tropical 47(1-2): 27-31.

Franceschi, V.R. \& Horner, H.T. 1980. Calcium oxalate crystals in plants. Botanical Review 46(4): 361-427.

Johansen, D.A. 1940. Plant microtechnique. McGraw-Hill Book Company, New York.

Kraus, J.E. \& Arduin, M. 1997. Manual básico de métodos em morfologia vegetal. Edur., Seropédica.

Kress, W.J. 1990a. The phylogeny and classification of the Zingiberales. Annals of the Missouri Botanical Garden 77(4): 698-721.

Kress, W.J. 1990b. The diversity and distribution of Heliconia (Heliconiaceae) in Brazil. Acta Botanica Brasilica 4(1): 159-167.

Kress, W.J.; Prince, L.M.; Hahn, W.J. \& Zimmer, E.A. 2001. Unraveling the evolutionary radiation of the families of the Zingiberales using morphological and molecular evidence. Systematic Biology 50(6): 926-944.

Metcalfe, C.R. 1969. Postscript and commentary. Pp. 414-421. In: C.R. Metcalfe (ed.). Anatomy of the Monocotyledons. Oxford University Press, Oxford.

Roeser, K.R. 1972. Die Nadel der Schwarzklefer-Masenprodukt und Kunstwert der Natur. Mikrokosmos 61: 33-36.

Rundel, P.W.; Sharifi, M.R.; Gibson, A.C. \& Esler, K.J. 1998. Structural and physiological adaptation to light environments in neotropical Heliconia (Heliconiaceae). Journal of Tropical Ecology 14: 789-801.

Sass, J.E. 1951. Botanical microtechnique. Iowa State College Press.

Simão, D.G. \& Scatena, V.L. 2001. Morphology and anatomy in Heliconia angusta Vell. and $H$. velloziana L. Emygd. (Zingiberales: Heliconiaceae) from the Atlantic forest of southeastern Brazil. Revista Brasileira de Botânica 24(4): 415-424.

Stebbins, G.L. \& Khush, G.S. 1961. Variation in the organization of the stomatal complex in the leaf epidermis of monocotyledons and its bearing on their phylogeny. American Journal of Botany 48(1): 51-59.

Thompson, V. 1997. Spittlebug nymphs (Homoptera: Cercopidae) in Heliconia flowers (Zingiberales: Heliconiaceae): Preadaptation and evolution of the first aquatic Homoptera. Revista de Biologia Tropical 45(2): 905-912. 
Tomlinson, P.B. 1959. An anatomical approach to the classification of the Musaceae. Journal of the Linnean Society (Botany) 55: 779-809.

Tomlinson, P.B. 1962. Phylogeny of the Scitamineae morphological and anatomical considerations. Evolution 16: $192-213$.

Tomlinson, P.B. 1969. III. Commelinales-Zingiberales. In: C.R. Metcalfe (ed.). Anatomy of the Monocotyledons. Oxford University Press, Oxford. 446p.
Tomlinson, P.B. 1974. Development of the stomatal complex as a taxonomic character in the monocotyledons. Taxon 23(1): 109-128.

Triplett, J.K. \& Kirchoff, B.K. 1991. Lamina architecture and anatomy in the Heliconiaceae and Musaceae (Zingiberales). Canadian Journal of Botany 69: 887-900.

Wootton, J.T. \& Sun, I.-F. 1990. Bract liquid as a herbivore defense mechanism for Heliconia wagneriana inflorescences. Biotropica 22(2): 155-159. 